\title{
High normal fasting glucose level in obese youth: a marker for insulin resistance and beta cell dysregulation
}

\author{
G. O'Malley • N. Santoro • V. Northrup • E. D'Adamo • \\ M. Shaw $\cdot$ S. Eldrich $\cdot$ S. Caprio
}

Received: 8 December 2009 /Accepted: 15 January 2010/Published online: 5 March 2010

(C) Springer-Verlag 2010

\begin{abstract}
Aims/hypothesis A high but normal fasting plasma glucose level in adults is a risk factor for future development of type 2 diabetes mellitus and cardiovascular disease. We investigated whether normal fasting plasma glucose levels $(<5.60 \mathrm{mmol} / \mathrm{l})$ are associated with decreases in insulin sensitivity and beta cell function, as well as an adverse cardiovascular profile in obese youth.

Methods We performed a cross-sectional analysis in a multiethnic sample of 1,020 obese youth (614 girls and 406 boys; mean age 12.9 years [CI 95\% 12.7-13.1], BMI $z$ score 2.34 [CI 95\% 2.31-2.38]) with normal fasting plasma glucose. All participants had a standard OGTT, with calculation of indices of insulin sensitivity and beta cell function. For the analysis, prepubertal and pubertal participants were stratified into quartiles of normal fasting plasma glucose.

Results We observed a significant increase in fasting insulin and AUC $2 \mathrm{~h}$ glucose across quartiles. Pronounced changes were observed in insulin sensitivity and secretion, particularly

G. O’Malley $\cdot$ N. Santoro $\cdot$ E. D'Adamo $\cdot$ M. Shaw $\cdot$ S. Eldrich $\cdot$

S. Caprio $(\varangle)$

Department of Pediatrics, Yale University School of Medicine,

330 Cedar Street, PO Box 208064,

New Haven, CT 06520, USA

e-mail: sonia.caprio@yale.edu

G. O'Malley

Departments of Endocrinology and Physiotherapy,

The Children's University Hospital,

Dublin, Ireland

\section{Northrup}

Yale Center for Clinical Investigation of Yale University School of Medicine, New Haven, CT, USA

\section{E. D'Adamo}

Department of Pediatrics,

University of Chieti, Chieti, Italy
\end{abstract}

in the pubertal group. Moreover, the odds of presenting with impaired glucose tolerance increased by $4.5 \%$ with each $0.06 \mathrm{mmol} / \mathrm{l}$ increase in fasting plasma glucose. No significant differences in cardiovascular indices were seen across quartiles. Conclusions/interpretation These data suggest that in obese youth, independent of age, BMI $z$ score, sex, family history and ethnicity, insulin sensitivity and secretion decline when moving from low to high normal fasting plasma glucose. The simple measure of fasting plasma glucose could assist clinicians in identifying children for targeted diabetes screening and subsequent lifestyle management.

Keywords Beta cell dysregulation · Fasting plasma glucose · Insulin resistance $\cdot$ Obesity $\cdot$ Type 2 diabetes

\begin{tabular}{|c|c|}
\hline \multicolumn{2}{|c|}{ Abbreviations } \\
\hline$\Delta$ glucose & $\begin{array}{l}\text { Mean change in glucose within the first } 30 \mathrm{~min} \\
\text { of the OGTT }\end{array}$ \\
\hline$\Delta$ insulin & $\begin{array}{l}\text { Mean change in insulin within the first } 30 \mathrm{~min} \\
\text { of the OGTT }\end{array}$ \\
\hline CVD & Cardiovascular disease \\
\hline DI & Disposition index \\
\hline FPG & Fasting plasma glucose \\
\hline IFG & Impaired fasting glucose \\
\hline IGI & Insulinogenic index \\
\hline IGT & Impaired glucose tolerance \\
\hline NFPG & Normal fasting plasma glucose \\
\hline WBISI & Whole body insulin sensitivity index \\
\hline
\end{tabular}

\section{Introduction}

According to the latest estimates from the International Obesity Taskforce, at least 155 million school-age children 
worldwide are overweight or obese [1]. Translated into clinical terms, this suggests that millions of children are now vulnerable to pathologies previously only seen in adults, such as type 2 diabetes mellitus, dyslipidaemia and hypertension. It is important that children at risk for such conditions be identified in order to implement effective management. Specifically, determining whether a child who is obese has a higher odds of presenting with risk factors known to lead to cardiometabolic disease is essential for the stratification of children to appropriate lifestyle interventions that improve the metabolic profile [2].

It has been demonstrated that impaired fasting glucose (IFG) is a clinical condition associated with a threefold increased risk of developing type 2 diabetes mellitus [3-7], and IFG status acts as a good marker of the acute insulin response and the disposition index (DI) $[8,9]$. Although the established thresholds for defining IFG may be considered to be quite low, recent reports have suggested that fasting plasma glucose (FPG) within the normal range (NFPG) is a significant risk factor for future development of type 2 diabetes mellitus in adults [3-7]. Studies examining the association between NFPG and the risk of metabolic disease in children are sparse, although recent reports suggest that high NFPG levels constitute an independent risk factor for diabetes [10]. Thus, before fasting glucose reaches the diagnostic range for IFG, impairments in the regulation of glucose homeostasis might already exist. Studies investigating the association between NFPG and the risk of cardiovascular disease (CVD) are limited in adults $[3,11,12]$ and even more sparse in children [10]. The aim of the present study was to investigate whether NFPG levels in a large multiracial sample of obese children and adolescents could act as a marker of metabolic and cardiovascular deterioration. It was hypothesised that in obese youth, as FPG rises within the normal range, the odds of presenting with decreased insulin sensitivity, beta cell dysregulation and cardiovascular disease profile would be greater.

\section{Methods}

\section{Study population}

We performed a cross-sectional study of metabolic and cardiovascular risks factors in 1,377 obese children and adolescents (BMI $>95$ th percentile for age and sex) referred to the Yale Pediatric Obesity and Lipid Disorders Clinic from 2000 to 2008. Obese children and adolescents are referred to our clinic by local community paediatricians in the area of New Haven, CT. Eligibility for the study was determined by a comprehensive medical examination before enrolment. The physical examination included determination of the stage of puberty according to the criteria of Tanner. All participants underwent an OGTT at baseline, before starting any treatment or intervention. We excluded 272 children whose FPG was greater than or equal to $5.6 \mathrm{mmol} / \mathrm{l}$ and 85 children who had a previous history of impaired glucose tolerance, abnormal thyroid function or previous use of any medication known to affect glucose, blood pressure or lipid metabolism. In addition, information regarding a family history of type 2 diabetes mellitus was collected. The final sample included 1,020 children and adolescents with NFPG. The study protocol was approved by the institutional review board of the Yale University School of Medicine, and written parental consent and child assent were obtained before the study.

\section{Testing procedures}

A standard OGTT was performed in all children and adolescents to establish glucose tolerance status. Subjects were studied at the Hospital Research Unit at the Yale University School of Medicine at 08:00 hours, after a $10 \mathrm{~h}$ overnight fast. Children were advised to follow a meal plan that included $>250 \mathrm{~g}$ of carbohydrate per day for 7 days before testing, and on the day before the OGTT they were advised to refrain from strenuous activity. Body weight, percentage body fat and BMI were measured using a Body Fat Analyzer (Tanita Corporation, Arlington Heights, IL, USA); and height was measured in triplicate with a wall-mounted stadiometer. Blood pressure was measured three times with a sphygmomanometer (model 01752, American Diagnostics, Hauppauge, NY, USA) while the participants were seated, and the last two measurements were averaged for analysis. After the local application of a topical anaesthetic cream containing $2.5 \%$ lidocaine and $2.5 \%$ prilocaine, one antecubital intravenous catheter was inserted for blood sampling and was maintained patent by a saline drip. Two baseline samples were then obtained at -15 and 0 min for measurements of plasma glucose, insulin and a fasting lipid profile. Thereafter, the participant drank a flavoured glucose drink (Custom Laboratories, Baltimore, MD, USA) containing $1.75 \mathrm{~g}$ glucose $/ \mathrm{kg}$ body weight, to a maximum of $75 \mathrm{~g}$ of glucose. Subsequent blood samples were obtained for measurement of glucose and insulin levels at 30, 60, 90, 120 and $180 \mathrm{~min}$. Impaired glucose tolerance (IGT) and type 2 diabetes mellitus were defined according to American Diabetes Association guidelines [13].

\section{Biochemical analyses}

Plasma glucose was determined using the YSI 2700 Stat Analyzer (Yellow Springs Instruments, Yellow Springs, $\mathrm{OH}$, USA). Plasma insulin was measured using RIA assays (Linco Research, St Charles, MO, USA) and lipid levels were measured with the use of an auto-analyser (model 747-200, Roche Hitachi, Indianapolis, IN, USA). 


\section{Calculations from the OGTT}

Indices of insulin sensitivity The whole body insulin sensitivity index (WBISI) is a surrogate measure of insulin sensitivity, which we have previously described and validated against the euglycaemic-hyperinsulinaemic clamp in obese children and adolescents $[14,15]$. The total AUC for glucose during OGTT $\left(\mathrm{AUC}_{2 \mathrm{~h}}\right.$ glucose $)$ was calculated using the trapezoidal (trapezium) rule [16], and that number was then divided by $120 \mathrm{~min}$ to obtain an average level during OGTT.

Beta cell function The insulinogenic index (IGI), which represents early phase insulin secretion and is a commonly used surrogate index of beta cell function, was calculated from the OGTT data: $\mathrm{IGI}=\Delta$ insulin $(0-30 \mathrm{~min})$ in $\mu \mathrm{U} / \mathrm{ml}$ divided by the $\Delta$ glucose ( $0-30 \mathrm{~min}$ ) in $\mathrm{mg} / \mathrm{dl}$ (to convert IGI to SI units [pmol/mmol], multiply by 125.01$)$. The DI was calculated as the product of the IGI and the WBISI, based on the curvilinear relation of these OGTT-derived variables, previously described by our group in obese children and adolescents [17] (to convert DI to SI units $\left[1^{2} / \mathrm{mmol}^{2}\right]$, multiply by 324$)$.

Statistical analyses For the purpose of investigating the association between normal fasting plasma glucose and metabolic and cardiovascular risk factors, our sample was stratified into quartiles of NFPG. Quartiles were chosen, rather than the continuous distribution of NFPG, to address the somewhat skewed distribution of NFPG and for ease of clinical interpretation. Sample characteristics such as age, pubertal stage, height, weight, BMI $z$ score and percentage body fat were summarised and compared between the quartiles of NFPG using ANOVA. Post hoc pair-wise comparisons were made, adjusting the level of significance for multiple comparisons with the Bonferroni correction. Sex, family history of type 2 diabetes mellitus, race and pubertal status were compared using the $\chi^{2}$ test.

Multiple linear regression was used to evaluate the difference between the quartiles of NFPG in prepubertal and pubertal participants for each of the metabolic and cardiovascular risk factors, adjusting for age, sex, ethnicity and BMI $z$ score. Where appropriate, $\log$ transformations were used to normalise outcome variables with skewed distributions. Results are presented as least square means with $95 \%$ CIs, obtained from the multiple regression models. In a confirmatory analysis, NPFG was treated as a continuous variable in regression models assessing the presence of impaired insulin sensitivity and secretion or cardiovascular risks.

Logistic regression was also used to determine the probability of developing IGT/type 2 diabetes mellitus associated with each $\mathrm{mmol} / \mathrm{l}$ increase in FPG. Logistic regression models were adjusted for age, sex, ethnicity, pubertal status and BMI $z$ score. For both multiple and logistic regression, the models were also run using family history of type 2 diabetes mellitus; however, owing to a high number of missing values and very similar results, we excluded the variable. Results are presented as ORs with 95\% CIs. Statistical significance in the multiple regression and logistic regression models was established with an alpha of 0.05 , with appropriate corrections for multiple comparisons when required. Statistical analyses were performed with SAS (version 9.1; SAS Institute, Cary, NC, USA).

\section{Results}

Sample characteristics and fasting plasma glucose distribution by pubertal status

In total, 1,020 children and adolescents were included in the analyses. Of these, $60 \%$ were female, $37 \%$ were white, $33 \%$ were African-American and $30 \%$ were Hispanic. There were more pubertal children $(844,83 \%)$ in the cohort than prepubertal $(176,17 \%, p=0.04)$. The mean FPG for the full cohort was $5.00 \mathrm{mmol} / \mathrm{l}$ (range 3.42-5.54), and a significant difference $(p=0.003)$ was observed between the mean FPG of prepubertal (4.95 mmol/1, 95\% CI 4.90-5.00 mmol/l) and postpubertal children $(5.03 \mathrm{mmol} / 1,95 \%$ CI 5.00 $5.05 \mathrm{mmol} / \mathrm{l})$. A difference was also observed between the FPG distribution in prepubertal children and pubertal children $(p=0.02)$. Figure 1 presents the distribution of FPG in our study sample divided by pubertal status. No statistical differences were seen between quartiles for those children with a positive family history of type 2 diabetes mellitus based on data available from 850 children (Table 1).

Clinical characteristics of the study cohort according to FPG quartiles

All children were stratified into quartiles $(\mathrm{Q})$ of FPG (Q1 3.42-4.81 $\mathrm{mmol} / \mathrm{l}$; Q2 4.82-5.04 mmol/l; Q3 5.05$5.26 \mathrm{mmol} / \mathrm{l}$; and Q4 5.27-5.54 mmol/l). No differences were seen in mean and 95\% CIs for FPG between

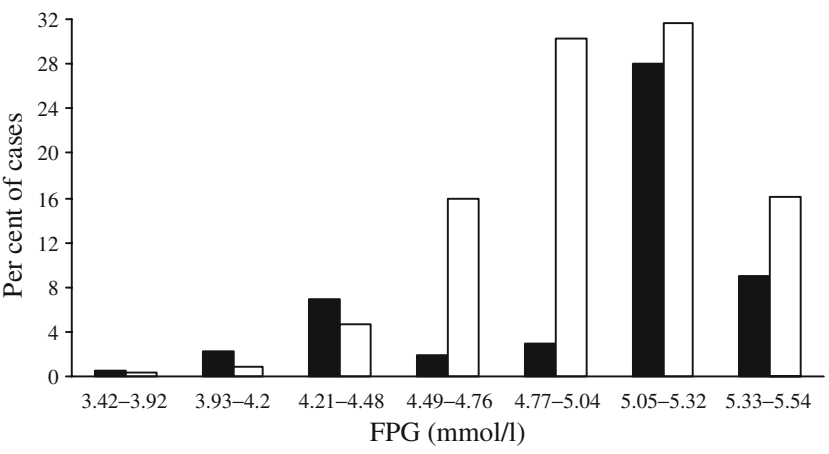

Fig. 1 Distribution of FPG throughout the normal range, stratified by pubertal status $(p=0.02)$. Black bars, prepubertal children; white bars, pubertal children 
Table 1 Clinical characteristics of the study cohort according to FPG quartile

\begin{tabular}{|c|c|c|c|c|c|}
\hline Characteristic & $\begin{array}{l}\text { Quartile } 1 \\
3.42-4.81 \mathrm{mmol} / 1 \\
(n=255)\end{array}$ & $\begin{array}{l}\text { Quartile } 2 \\
4.82-5.04 \mathrm{mmol} / 1 \\
(n=255)\end{array}$ & $\begin{array}{l}\text { Quartile } 3 \\
5.05-5.26 \mathrm{mmol} / \mathrm{l} \\
(n=255)\end{array}$ & $\begin{array}{l}\text { Quartile } 4 \\
5.27-5.54 \mathrm{mmol} / \mathrm{l} \\
(n=255)\end{array}$ & $p$ value $^{\mathrm{a}}$ \\
\hline \multicolumn{6}{|l|}{ Age (years) } \\
\hline \multicolumn{6}{|l|}{ Prepubertal } \\
\hline Mean & 7.9 & 8.5 & 8.7 & 8.8 & \multirow[t]{2}{*}{$0.01^{\mathrm{a}}$} \\
\hline $95 \% \mathrm{CI}$ & $7.5-8.2$ & $7.9-9.0$ & $8.3-9.0$ & $8.4-9.1$ & \\
\hline \multicolumn{6}{|l|}{ Pubertal } \\
\hline Mean & 13.9 & 13.8 & 13.8 & 13.8 & \multirow[t]{2}{*}{0.8} \\
\hline $95 \% \mathrm{CI}$ & $13.6-14.3$ & $13.5-14.1$ & $13.5-14.1$ & $13.5-14.1$ & \\
\hline \multicolumn{6}{|l|}{$\operatorname{Sex}(n, \%)$} \\
\hline Male & $77(30)$ & $103(40)$ & $107(42)$ & $119(47)$ & \multirow[t]{2}{*}{$<0.002^{b}$} \\
\hline Female & $178(70)$ & $152(60)$ & $148(58)$ & $136(63)$ & \\
\hline \multicolumn{6}{|l|}{ Pubertal status $(n, \%)$} \\
\hline Prepubertal & $57(22)$ & $46(18)$ & $43(16.5)$ & $33(13)$ & $0.03^{\mathrm{c}}$ \\
\hline Postpubertal & $198(88)$ & $209(82)$ & $212(83.5)$ & $222(87)$ & $0.03^{\mathrm{c}}$ \\
\hline \multicolumn{6}{|l|}{ Ethnicity $(n, \%)$} \\
\hline White & $116(46)$ & $89(35)$ & $101(40)$ & $91(36)$ & 0.1 \\
\hline African-American & $85(33)$ & $87(35)$ & $79(30)$ & $88(35)$ & 0.1 \\
\hline Hispanic & $54(21)$ & $79(30)$ & $75(30)$ & $76(29)$ & 0.1 \\
\hline \multicolumn{6}{|l|}{ +ve family hx T2DM } \\
\hline Prepubertal & 7 out of 43 & 13 out of 42 & 8 out of 39 & 7 out of 25 & 0.4 \\
\hline Postpubertal & 37 out of 161 & 40 out of 172 & 50 out of 184 & 44 out of 184 & 0.8 \\
\hline \multicolumn{6}{|l|}{ Height $(\mathrm{cm})$} \\
\hline \multicolumn{6}{|l|}{ Prepubertal } \\
\hline Mean & 134.9 & 140.1 & 137.8 & 141.6 & \multirow[t]{2}{*}{$0.02^{\mathrm{d}}$} \\
\hline $95 \% \mathrm{CI}$ & $131.8-138.1$ & $136.9-143.4$ & $134.6-141.1$ & $138.9-144.4$ & \\
\hline \multicolumn{6}{|l|}{ Pubertal } \\
\hline Mean & 160.4 & 160.6 & 161.4 & 163.8 & \multirow[t]{2}{*}{$0.001^{\mathrm{d}}$} \\
\hline $95 \% \mathrm{CI}$ & $158.9-161.8$ & $159.2-1661.9$ & $160.2-162.6$ & $162.4-165.1$ & \\
\hline \multicolumn{6}{|l|}{ Weight (kg) } \\
\hline \multicolumn{6}{|l|}{ Prepubertal } \\
\hline Mean & 57.8 & 61.2 & 56.3 & 63.7 & \multirow[t]{2}{*}{0.3} \\
\hline $95 \% \mathrm{CI}$ & $52.4-63.2$ & $55.0-67.4$ & $51.8-60.7$ & $58.6-68.9$ & \\
\hline \multicolumn{6}{|l|}{ Pubertal } \\
\hline Mean & 92.1 & 91.9 & 96.1 & 63.7 & \multirow[t]{2}{*}{0.04} \\
\hline $95 \% \mathrm{CI}$ & $88.4-95.7$ & $88.5-95.2$ & $92.6-99.6$ & $94.3-101.0$ & \\
\hline \multicolumn{6}{|l|}{ BMI SDS } \\
\hline \multicolumn{6}{|l|}{ Prepubertal } \\
\hline Mean & 2.62 & 2.46 & 2.49 & 2.56 & 0.3 \\
\hline $95 \% \mathrm{CI}$ & $2.5-2.73$ & $2.3-2.62$ & $2.35-2.63$ & $2.47-2.6$ & \\
\hline Pubertal & & & & & \\
\hline Mean & 2.21 & 2.28 & 2.35 & 2.36 & $0.02^{\mathrm{e}}$ \\
\hline $95 \% \mathrm{CI}$ & $2.13-2.3$ & $2.21-2.36$ & $2.29-2.41$ & $2.29-2.42$ & \\
\hline Percentage body fat & & & & & \\
\hline Prepubertal & & & & & \\
\hline Mean & 46.1 & 44.6 & 44.9 & 46.2 & 0.8 \\
\hline $95 \% \mathrm{CI}$ & $42.5-49.8$ & $42.5-47.6$ & $42.1-47.6$ & $42.8-49.7$ & \\
\hline Pubertal & & & & & \\
\hline Mean & 44.3 & 44.6 & 45.6 & 44.4 & 0.5 \\
\hline $95 \% \mathrm{CI}$ & $42.7-45.9$ & $43.3-45.8$ & $44.3-46.9$ & $43.2-45.6$ & \\
\hline
\end{tabular}


Table 1 (continued)

\begin{tabular}{cllll}
\hline Characteristic & $\begin{array}{l}\text { Quartile 1 } \\
3.42-4.81 \mathrm{mmol} / \mathrm{l} \\
(n=255)\end{array}$ & $\begin{array}{l}\text { Quartile } 2 \\
4.82-5.04 \mathrm{mmol} / \mathrm{l} \\
(n=255)\end{array}$ & $\begin{array}{l}\text { Quartile 3 }_{5.05-5.26 \mathrm{mmol} / \mathrm{l}} \\
(n=255)\end{array}$ & $\begin{array}{l}\text { Quartile } 4_{5.27-5.54 \mathrm{mmol} / 1} \\
(n=255)\end{array}$ \\
\hline IGT status $(n, \%)$ & & & & \multicolumn{1}{c}{ value $^{\mathrm{a}}$} \\
Prepubertal & $5(18)$ & $4(17)$ & $6(17)$ & $4(10)$ \\
FPG mean & 4.49 & 4.92 & 5.14 & 5.40 \\
FPG 95\% CI & $4.31-4.67$ & $4.83-5.00$ & $5.06-5.23$ & $5.29-5.52$ \\
Pubertal & $23(82)$ & $20(83)$ & $30(83)$ & $38(90)$ \\
FPG mean & 4.59 & 4.96 & 5.16 & 5.41 \\
FPG 95\% CI & $4.48-4.69$ & $4.92-4.99$ & $5.14-5.19$ & $5.38-5.44$ \\
\hline
\end{tabular}

+ve family hx T2DM, positive family history of type 2 diabetes mellitus; BMI SDS, body mass index standard deviation score

${ }^{a}$ Post hoc pair-wise comparisons showed a significant difference between Q1 and Q3 ( $\left.p=0.03\right)$ and between Q1 and Q4 ( $p=0.03$ )

${ }^{\mathrm{b}}$ Post hoc pair-wise comparisons showed that there was a significantly greater proportion of girls to boys between Q1 and Q2 ( $\left.p<0.001\right)$, Q1 and Q3 $(p<0.001), \mathrm{Q} 1$ and Q4 $(p<0.001), \mathrm{Q} 2$ and Q4 $(p<0.05)$

${ }^{\mathrm{c}}$ Post hoc pair-wise comparisons showed that there was a significantly greater proportion of pubertal to prepubertal children between Q1 and Q3 $(p=0.07)$ and Q1 and Q4 $(p=0.005)$

${ }^{\mathrm{d}}$ Post hoc pair-wise comparisons showed a significant difference between Q1 and Q4 ( $\left.p=0.04\right)$ for prepubertal children and between Q1 and Q4 $(p=0.002)$ and Q2 and Q4 ( $p=0.02)$ for pubertal children

${ }^{\mathrm{e}}$ Post hoc pair-wise comparisons showed a significant difference between Q1 and Q3 ( $\left.p=0.05\right)$ and Q1 and Q4 ( $\left.p=0.04\right)$ in pubertal children

${ }^{\mathrm{f}}$ Post hoc pair-wise comparisons of prepubertal and pubertal children showed no difference between mean FPG values

prepubertal and pubertal children in each quartile $(\mathrm{Q} 1$ $4.57 \mathrm{mmol} / 1[95 \%$ CI $4.50-4.63 \mathrm{mmol} / 1]$ and $4.60 \mathrm{mmol} / 1$ [95\% CI 4.57-4.63 mmol/l]; Q2 $4.94 \mathrm{mmol} / 1$ [95\% CI $4.92-$ $4.96 \mathrm{mmol} / 1]$ and $4.92 \mathrm{mmol} / 1$ [95\% CI 4.91-4.93 mmol/1]; Q3 $5.16 \mathrm{mmol} / 1[95 \% \mathrm{CI} 5.13-5.18 \mathrm{mmol} / 1]$ and $5.14 \mathrm{mmol} / \mathrm{l}[95 \%$ CI 5.13-5.15 mmol/1]; and Q4 $5.37 \mathrm{mmol} / 1$ [95\% CI 5.35$5.41 \mathrm{mmol} / 1]$ and $5.39 \mathrm{mmol} / 1$ [95\% CI $5.38-5.40 \mathrm{mmol} / \mathrm{l}]$ ).

Table 1 provides the basic anthropometric data for the study cohort according to FPG quartiles. No significant differences were seen between the quartiles for race and percentage body fat. Significant differences were observed for sex, pubertal status, height, weight and BMI standard deviation score (pubertal children only).

Prevalence of IGT and type 2 diabetes mellitus across quartiles of FPG

After the OGTT, 128 children (12.4\%) were diagnosed with IGT and two children were diagnosed with type 2 diabetes mellitus. Of those with IGT, 19 were prepubertal (14.8\%); $83(64.8 \%)$ were girls (seven prepubertal); 29 (22.7\%) were African-American and 29 (22.7\%) were Hispanic (Table 1). For the statistical analysis, the two participants with diabetes were included with those with IGT.

Insulin sensitivity and secretion indices across quartiles of FPG

In both pre- and pubertal groups we found an increase in fasting insulin across quartiles of NFPG (Fig. 2a, b).
Notably, however, these increases were more pronounced in the pubertal group. The AUC for $2 \mathrm{~h}$ glucose increased progressively with rising NFPG in both pre- and pubertal groups (Fig. 2c, d). Insulin sensitivity (WBISI) decreased progressively as NFPG levels increased, independently of age, sex, ethnicity and BMI $z$ score (Fig. 3a, b). These changes were, however, greater and more significant in the pubertal group $(p<0.001)$. Despite an unchanged IGI in both groups, we found a decrease in the DI only in the pubertal group ( $p<0.001$; Fig. 3 e, f). Similarly, regression analyses using NFPG as a continuous variable agreed with our observations using quartiles of NFPG.

\section{Cardiovascular indices according to FPG}

No statistically significant differences in cardiovascular indices were seen across the quartiles of FPG (Table 2).

Risk of impaired glucose tolerance, insulin sensitivity and beta cell function

The odds of presenting with IGT/type 2 diabetes mellitus in Q3 and Q4 for NFPG vs Q1 and Q2 for prepubertal and pubertal children, respectively, was 1.07 (95\% CI $0.33-$ $3.58 ; p=0.8)$ and $1.64(95 \%$ CI $1.06-2.52 ; p=0.002)$ Moreover, for the full cohort, each $0.06 \mathrm{mmol} / 1$ increase in FPG was associated with an increased odds of presenting with IGT/type 2 diabetes mellitus of $4.5 \%$ (OR $1.045,95 \%$ CI 1.009-1.08; $p=0.001$ ). 

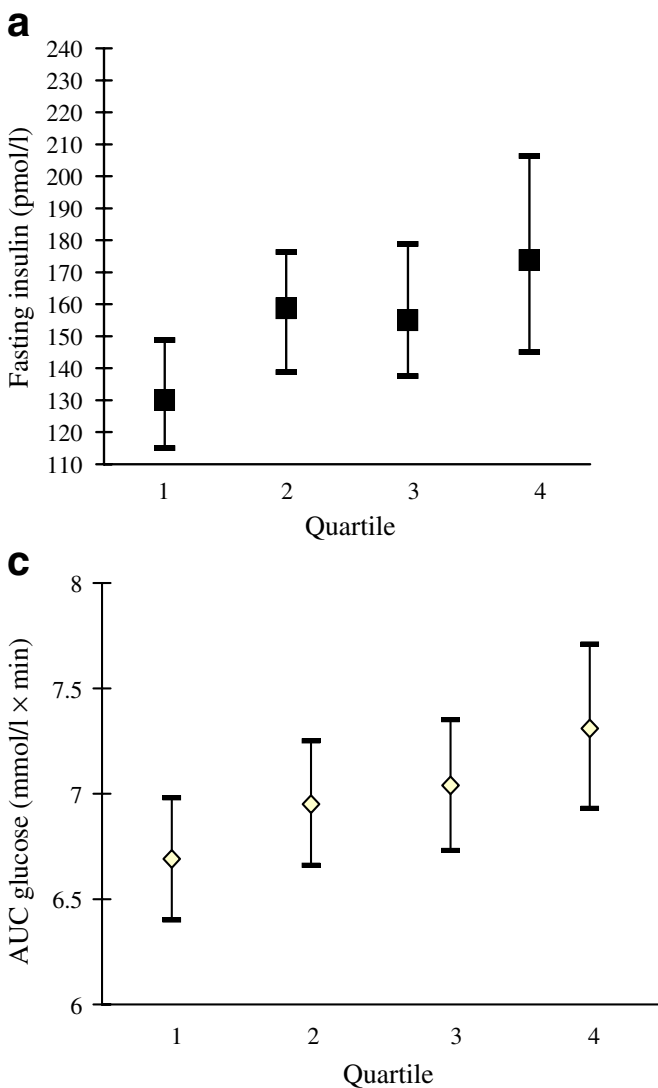

Fig. 2 A multiple linear regression approach was used to evaluate the effect of quartiles of FPG levels on each outcome of interest, adjusting for age, sex, pubertal status, ethnicity and BMI $z$ score. Geometric means and surrounding CIs obtained from the models are presented. The statistical significance of differences in the outcomes by the four quartiles of fasting plasma glucose is expressed by the $p$ value from the omnibus test. a Mean fasting insulin across quartiles of FPG in prepubertal children; $p=0.3$. b Mean fasting insulin across quartiles of

\section{Discussion}

In this cross-sectional study we evaluated whether rising NFPG levels were associated with pathophysiological cardiovascular and metabolic alterations. Our results indicated that in obese adolescents insulin sensitivity and beta cell function decrease significantly with increasing NFPG, independently of sex, ethnicity and BMI $z$ score. In particular, we observed a significant increase in fasting plasma insulin and AUC $2 \mathrm{~h}$ glucose and a decrease in WBISI and DI across quartiles of NFPG. These changes were less pronounced in obese prepubertal children. As such, we found that despite having an NFPG, derangements in insulin sensitivity and beta cell function were still observed in obese youth. The fact that we observed significant decreases in insulin sensitivity and DI in the pubertal group is consistent with the higher prevalence rates of type 2 diabetes mellitus reported for this age group by the SEARCH study [18].
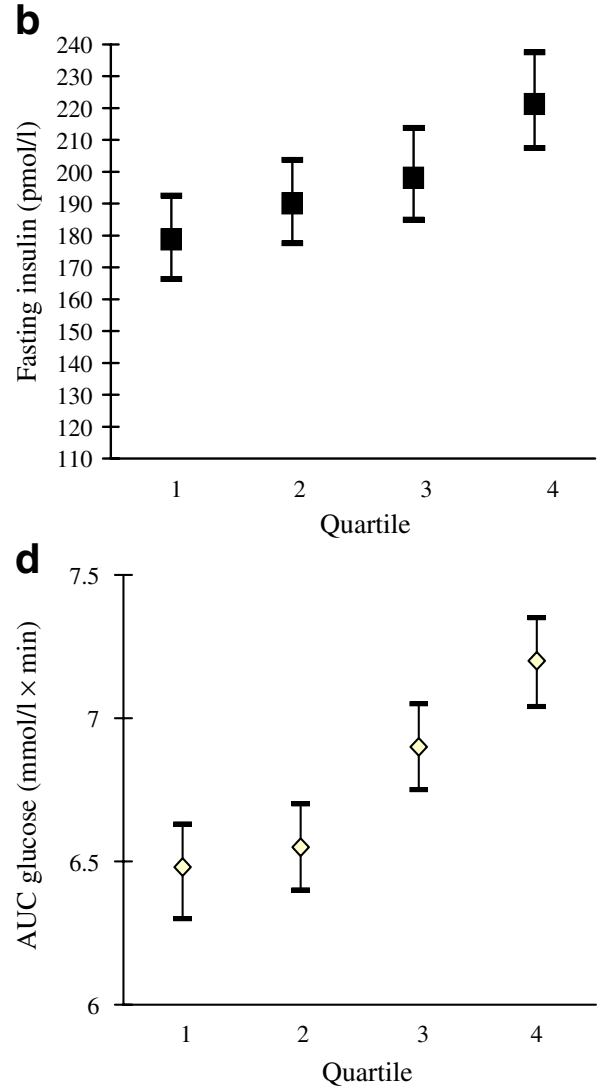

FPG in pubertal children; $p<0.001$. c Mean AUC $2 \mathrm{~h}$ glucose across quartiles of FPG in prepubertal children; $p=0.04$. d Mean AUC $2 \mathrm{~h}$ glucose across quartiles of FPG in pubertal children; $p<0.001$. Significant post hoc pair-wise comparisons: (1) AUC $2 \mathrm{~h}$ glucose: $\mathrm{Q} 1$ vs $\mathrm{Q} 3, p<0.001 ; \mathrm{Q} 1$ vs $\mathrm{Q} 4, p<0.001 ; \mathrm{Q} 2$ vs $\mathrm{Q} 3, p<0.001$; Q2 vs $\mathrm{Q} 4, p<0.001$; Q3 vs $44, p=0.025$. (2) Fasting insulin in pubertal children: Q1 vs Q4, $p<0.001$; Q2 vs Q4, $p=0.008$

It should be noted that, although pubertal stage was not different across the quartiles, in the pubertal group the degree of obesity was significantly greater in quartile four than in quartile one $(p<0.02)$. Therefore, although we adjusted for $\mathrm{BMI} z$ score, it is conceivable that the worsening in insulin resistance and secretion may have resulted from the greater severity of obesity in quartile four. Nevertheless, we argue that these changes are not a result of puberty, as we also observed a similar, although less pronounced, trend in the smaller group of prepubertal children.

Whether the rise in FPG reflects a derangement in insulin sensitivity and secretion or simply physiological variability, is an important issue that needs to be addressed. One should bear in mind that these results are obtained by using surrogate measures of insulin sensitivity and secretion obtained by OGTT as it would be difficult to evaluate insulin secretion and sensitivity in such a large sample of obese youth by using the gold standard euglycaemichyperinsulinaemic clamp for sensitivity and hyperglycae- 
a

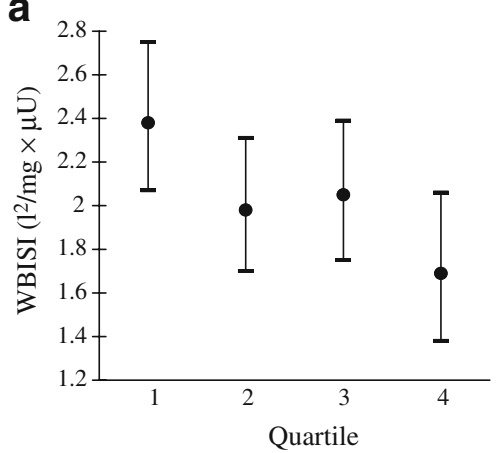

C
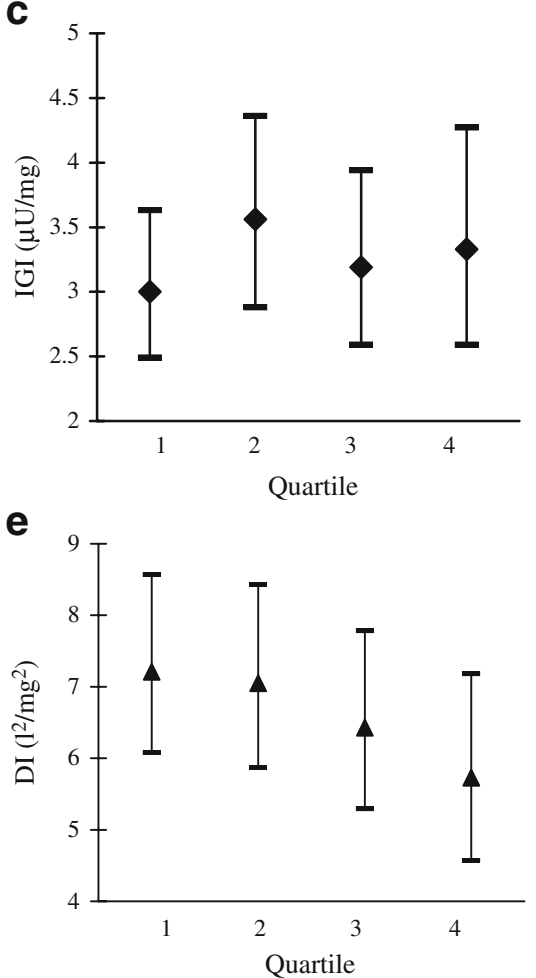

b

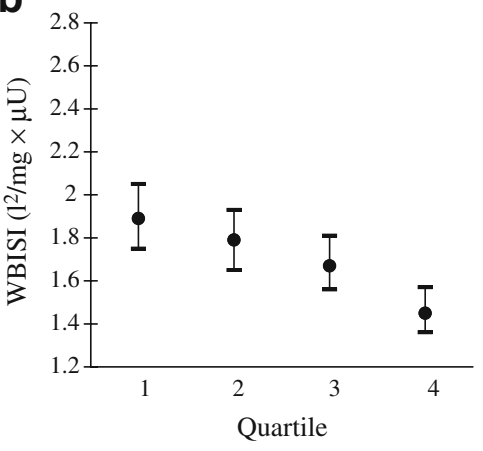

d

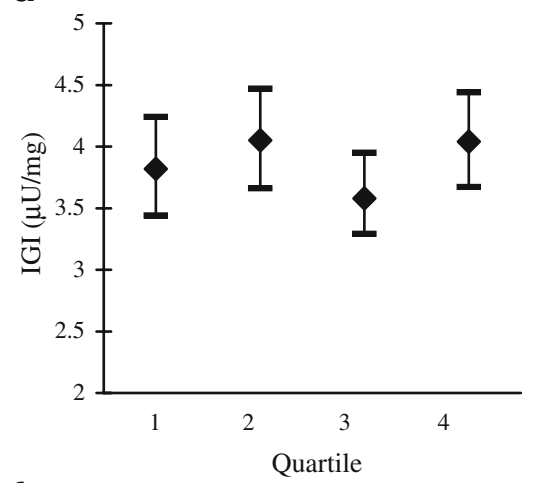

f

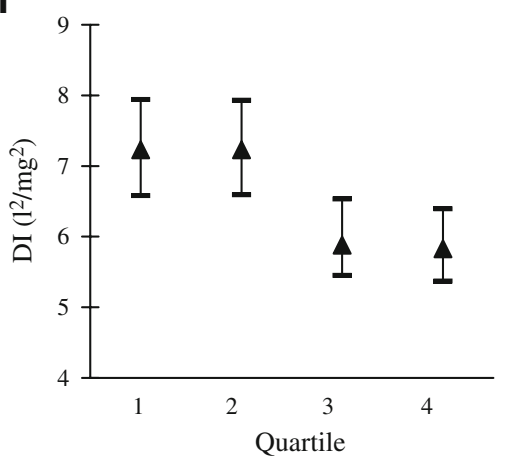

Fig. 3 A multiple linear regression approach was used to evaluate the effect of quartiles of FPG levels on each outcome of interest, adjusting for age, sex, pubertal status, ethnicity and BMI $z$ score. Geometric means and surrounding CIs obtained from the models are presented. The statistical significance of differences in the outcomes by the four quartiles of FPG is expressed by the $p$ value from the omnibus test. a Mean WBISI across quartiles of FPG in prepubertal children; $p=0.05$. b Mean WBISI across quartiles of FPG in pubertal children; $p=0.003$. c Mean IGI across quartiles of FPG in prepubertal children; $p=0.9$. d Mean IGI across quartiles of FPG in pubertal children; $p=0.4$. e Mean

mic clamp for secretion. Of note, however, is that the OGTT-derived indices of insulin resistance (WBISI) and secretion (IGI) employed in the current study were validated by our group and were found to correlate relatively well with clamp-derived insulin sensitivity and secretion measures in obese children and adolescents $[15$, 19]. Reproducibility of the OGTT as a tool to detect glucose regulation is known to be poor, particularly for $2 \mathrm{~h}$ plasma glucose [20]. Such variability of the OGTT is not
DI across quartiles of FPG in prepubertal children; $p=0.4$. f Mean DI across quartiles of FPG in pubertal children; $p<0.001$. Significant post hoc pair-wise comparisons: (1) WBISI: For prepubertal children, Q1 vs Q4, $p=0.04$. For pubertal children, Q1 vs Q4, $p<0.001$; Q2 vs Q4, $p<0.001$; $\mathrm{Q} 3$ vs $\mathrm{Q} 4, p=0.05$. (2) DI in pubertal children: Q1 vs Q3, $p=0.02$; Q1 vs $\mathrm{Q} 4, p=0.01 ; \mathrm{Q} 2$ vs $\mathrm{Q} 3, p=0.02 ; \mathrm{Q} 2$ vs $\mathrm{Q} 4, p<0.01$. To convert WBISI to SI units $\left(1^{2} / \mathrm{mmol} \times \mathrm{pmol}\right)$, multiply by 2.5918 ; to convert IGI to SI units (pmol/mmol), multiply by 125.01 ; to convert DI to SI units $\left(1^{2} / \mathrm{mmol}^{2}\right)$, multiply by 324

surprising, given that basal and postprandial measures of glucose and insulin are highly variable, reflecting changes in nutrition and physical activity, and are influenced by seasonal and diurnal factors. Goran et al. [21], using a longitudinal design, found that the pattern of prediabetes over time is highly variable from year to year and that the prevalence of persistent prediabetes is estimated to be $13 \%$. Furthermore, they observed that persistent prediabetes is associated with compromised beta cell function, a 
Table 2 Cardiovascular indices according to FPG quartile

\begin{tabular}{|c|c|c|c|c|c|}
\hline Characteristic & $\begin{array}{l}\text { Quartile } 1 \\
3.42-4.81 \mathrm{mmol} / 1 \\
n=255\end{array}$ & $\begin{array}{l}\text { Quartile } 2 \\
4.82-5.04 \mathrm{mmol} / 1 \\
n=255\end{array}$ & $\begin{array}{l}\text { Quartile } 3 \\
5.05-5.26 \mathrm{mmol} / 1 \\
n=255\end{array}$ & $\begin{array}{l}\text { Quartile } 4 \\
5.27-5.54 \mathrm{mmol} / 1 \\
n=255\end{array}$ & $p$ value $^{\mathrm{a}}$ \\
\hline \multicolumn{6}{|l|}{ Cholesterol $^{\mathrm{b}}$} \\
\hline \multicolumn{6}{|l|}{ Prepubertal } \\
\hline Mean & 4.43 & 4.09 & 4.30 & 4.16 & 0.2 \\
\hline $95 \% \mathrm{CI}$ & $4.12-4.74$ & $3.80-4.74$ & $4.01-4.60$ & $3.78-4.53$ & \\
\hline \multicolumn{6}{|l|}{ Pubertal } \\
\hline Mean & 4.11 & 4.23 & 3.99 & 4.09 & 0.1 \\
\hline $95 \% \mathrm{CI}$ & $3.96-4.27$ & $4.09-4.37$ & $3.85-4.13$ & $3.95-4.23$ & \\
\hline \multicolumn{6}{|l|}{$\mathrm{LDL}^{\mathrm{b}}$} \\
\hline \multicolumn{6}{|l|}{ Prepubertal } \\
\hline Mean & 2.69 & 2.44 & 2.48 & 2.50 & 0.5 \\
\hline $95 \% \mathrm{CI}$ & $2.43-2.95$ & $2.21-2.68$ & $2.23-2.73$ & $2.19-2.80$ & \\
\hline \multicolumn{6}{|l|}{ Pubertal } \\
\hline Mean & 2.41 & 2.49 & 2.32 & 2.38 & 0.3 \\
\hline $95 \% \mathrm{CI}$ & $2.28-2.54$ & $2.37-2.62$ & $2.20-2.43$ & $2.26-2.50$ & \\
\hline \multicolumn{6}{|l|}{$\mathrm{HDL}^{\mathrm{b}}$} \\
\hline \multicolumn{6}{|l|}{ Prepubertal } \\
\hline Mean & 1.15 & 1.07 & 1.23 & 1.14 & 0.1 \\
\hline $95 \% \mathrm{CI}$ & $1.06-1.24$ & $0.99-1.16$ & $1.14-1.32$ & $1.03-1.25$ & \\
\hline \multicolumn{6}{|l|}{ Pubertal } \\
\hline Mean & 1.09 & 1.12 & 1.13 & 1.16 & 0.6 \\
\hline $95 \% \mathrm{CI}$ & $1.04-1.13$ & $1.08-1.16$ & $1.09-1.17$ & $1.08-1.16$ & \\
\hline \multicolumn{6}{|c|}{ Triacylglycerol $^{\mathrm{b}}$} \\
\hline \multicolumn{6}{|l|}{ Prepubertal } \\
\hline Mean & 1.27 & 1.18 & 1.19 & 1.07 & 0.7 \\
\hline $95 \% \mathrm{CI}$ & $1.03-1.51$ & $0.96-1.40$ & $0.96-1.42$ & $0.78-1.35$ & \\
\hline \multicolumn{6}{|l|}{ Pubertal } \\
\hline Mean & 1.35 & 1.39 & 1.24 & 1.30 & 0.8 \\
\hline $95 \% \mathrm{CI}$ & $1.15-1.54$ & $1.21-1.58$ & $1.07-1.42$ & $1.13-1.48$ & \\
\hline \multicolumn{6}{|c|}{ Systolic BP (mmHg) } \\
\hline \multicolumn{6}{|l|}{ Prepubertal } \\
\hline Mean & 116.9 & 114.6 & 115.4 & 115.1 & 0.8 \\
\hline $95 \% \mathrm{CI}$ & $113.2-120.5$ & $111.2-118.5$ & $111.5-119.3$ & $110.6-111.7$ & \\
\hline \multicolumn{6}{|l|}{ Pubertal } \\
\hline Mean & 120.6 & 121.1 & 121.5 & 121.9 & 0.4 \\
\hline $95 \% \mathrm{CI}$ & $118.9-122.4$ & $119.5-122.8$ & $119.8-123.1$ & $120.3-123.5$ & \\
\hline \multicolumn{6}{|c|}{ Diastolic BP (mmHg) } \\
\hline \multicolumn{6}{|l|}{ Prepubertal } \\
\hline Mean & 67.5 & 68.5 & 67.7 & 66.4 & 0.8 \\
\hline $95 \% \mathrm{CI}$ & $64.2-70.7$ & $65.2-71.9$ & $64.2-71.2$ & $62.3-7.5$ & \\
\hline \multicolumn{6}{|l|}{ Pubertal } \\
\hline Mean & 67.5 & 68.5 & 67.7 & 66.4 & 0.8 \\
\hline $95 \% \mathrm{CI}$ & $68.5-71.4$ & $69.9-72.6$ & $70.0-72.7$ & $69.9-72.6$ & \\
\hline
\end{tabular}

${ }^{\mathrm{a}} p$ value obtained from a multiple linear regression, adjusted for age, sex, pubertal status, ethnicity and BMI $z$ score

${ }^{\mathrm{b}}$ Variables were $\log _{e}$-transformed for analysis 
lower than expected acute insulin response subsequent to progressive insulin resistance, and a greater accumulation of visceral fat over time. Our group, using three serial OGTTs over a 3-year period in obese adolescents with normal glucose tolerance at baseline, observed remarkable stability in insulin sensitivity, beta cell function and DI [22]. By contrast, a decline in sensitivity, secretion and DI occurred in those obese adolescents that progressed to IGT. Thus, we consider that the described changes in insulin sensitivity and DI seen with rising NFPG in the present study are a true reflection of derangements in metabolism.

Our finding that high NFPG levels are correlated with reduced insulin sensitivity and beta cell dysfunction is supported by previous reports in adults that identified higher NFPG levels as an independent risk factor for impaired insulin secretion and type 2 diabetes mellitus in adults $[6,8]$. Although our results are similar to those reported in adult studies, it is important to consider that the development of type 2 diabetes mellitus is a recent phenomenon observed in paediatrics. As such, investigations into the similarities and differences in pathological processes observed between children and adults are important, particularly if optimal therapy is to be implemented in childhood. A report from the Bogalusa Heart Study observed that adults who developed IGT or type 2 diabetes mellitus had higher glucose levels from childhood to adulthood compared with those adults who were normoglycaemic [12]. Also, a recent longitudinal study by Tirosh et al. [5] reported that high NFPG levels constituted an independent risk factor for the development of type 2 diabetes mellitus within a 10 -year follow-up period. It is conceivable that some individuals may have an innate impaired beta cell capacity to compensate for insulin resistance. In fact, recent association studies, using powerful tools such as the genome-wide scan, produced a list of several genes associated with type 2 diabetes mellitus, the majority of which appear to be mainly implicated in beta cell function [23].

Nichols et al. observed a $6 \%$ increased risk of developing diabetes with each $0.06 \mathrm{mmol} / \mathrm{l}$ increase in FPG in a large group of adults [4]. Our results support the findings of this report, as our data indicated a $4.5 \%$ increased risk for presenting with IGT in adolescents with every $0.05 \mathrm{mmol} / \mathrm{l}$ increase in FPG. To our knowledge, this is the first investigation to report such data in a population of obese youth. Nichols and colleagues indicated that those with an FPG level between 5 and $5.56 \mathrm{mmol} / \mathrm{l}$ had a greater disease risk than those with an $\mathrm{FPG}<4.72 \mathrm{mmol} / \mathrm{l}$, which further supports the findings of the current study.

The evaluation of beta cell function is important in clinical practice, although estimating this index can be time-consuming and somewhat impractical. A close relationship exists between FPG and beta cell function, and increasing levels of NFPG have been associated with a $32 \%$ decrease in the beta cell function of adults [7, 17]. Recently, DI has been shown to be predictive of the development of diabetes over 10 years [9]. The results of our investigation indicated that there is an increased risk of beta cell dysfunction with a decline in DI as NFPG increases.

Previous investigations suggest that FPG level is a risk marker for cardiovascular disease [3, 24]. Results from both the Diabetes Control and Complications Trial and the UK Prospective Diabetes Study Group support the use of appropriate glycaemic control for the prevention of atherosclerosis, and more recently these recommendations have been reasserted for youth with type 2 diabetes mellitus [2527]. In addition, at 10-year follow up, longitudinal analyses observed the cardiovascular benefits of glucose control in adults with newly diagnosed type 2 diabetes mellitus [28]. Preventing atherosclerosis through better glucose control is a contentious topic, and in some epidemiologic studies the association between glucose control and cardiovascular disease has not been consistent [29-32]. Moreover, it has been shown that intensive glucose control in veterans with poorly controlled type 2 diabetes had no significant effect on the rates of major cardiovascular events, death or microvascular complications, with the exception of progression of albuminuria [33]. Few studies have investigated the relationship between normoglycaemia and risk factors for cardiovascular disease, although a report by Piche et al. [3] observed that higher triacylglycerol levels and reduced HDLcholesterol were present in adults with high NFPG compared with those with lower NFPG. Contrary to these reports but in agreement with previous paediatric investigation, data from our study suggest that in children increases in FPG within the normal range are not associated with an increase in the cardiovascular risk profile [10]. This was also the case when the group was further divided by ethnicity (data not shown). The differences between adult and paediatric data may be ascribed to the younger age of participants included in our study and to their relatively short exposure to the hyperinsulinaemic environment. As such, it could be postulated that adverse effects in glucose metabolism may occur earlier than an adverse cardiovascular profile in children who are in the metabolically stressful state of obesity, which may require a longer period of exposure to hyperglycaemia and associated insulin resistance. If this is the case, a critical window of opportunity for effective treatment before the onset of cardiovascular damage might be available to clinicians when a child presents with a high NFPG.

Although the provision of a 'cut-off point' for normal glucose level was beyond the purpose of our study, the distribution of measured variables across quartiles of NFPG clearly shows that those children in quartile four display a higher risk for metabolic derangement. This suggests that FPG levels higher than $5.17 \mathrm{mmol} / \mathrm{l}$ might indicate a 'danger zone' for adolescents, given that after this level the 
risk of IGT increases by $64 \%$ compared with those participants in the first three quartiles. As current paediatric definitions for IGT and IFG are based on adult studies, our data suggests that the 'cut-off point' for abnormality may be lower in children and adolescents, and thus represents a clinically meaningful observation.

As our sample was drawn from a clinical population in New Haven, these cross-sectional results may not be representative of the general paediatric population, although these children do reflect what general paediatricians are seeing in their daily practice. Similarly, our findings may not be applicable to those children of healthy weight. Furthermore, this study is a retrospective one and, as such, has all the limitations known to be associated with such investigations.

These data suggest that in prepubertal and pubertal obese youth insulin sensitivity declines when moving from low to high NFPG, independently of age, BMI, sex and ethnicity. Recent studies have demonstrated that lifestyle intervention can reduce risk factors for, and the incidence of, type 2 diabetes mellitus in children and adults and that those individuals presenting with prediabetes can convert back to normal glucose tolerance with appropriate lifestyle management $[2,34,35]$. Thus, FPG may be a useful measure for identifying children with higher odds of presenting with metabolic impairment and might be useful to identify those for whom subsequent targeted therapeutic lifestyle management would be most beneficial.

Acknowledgements This study was supported by grants from the National Institutes of Health (NIH) (R01-HD40787, R01-HD28016 and K24-HD01464 to S. Caprio), and by CTSA Grant Number UL1 RR0249139 from the National Center for Research Resources (NCRR), a component of the National Institutes of Health. This publication and its contents are solely the responsibility of the authors and do not necessarily represent the official views of the NCRR or NIH. Thanks also to The Fulbright Commission for funds related to this study granted to G. O'Malley.

Duality of interest The authors declare that there is no duality of interest associated with this manuscript.

\section{References}

1. Lobstein T, Baur L, Uauy R (2004) Obesity in children and young people: a crisis in public health. Obes Rev 5:4-104

2. Shaw M, Savoye M, Cali A, Dziura J, Tamborlane WV, Caprio S (2009) Effect of a successful intensive lifestyle program on insulin sensitivity and glucose tolerance in obese youth. Diabetes Care 32:45-47

3. Piche ME, Lemieux S, Perusse L, Weisnagel SJ (2005) High normal 2-hour plasma glucose is associated with insulin sensitivity and secretion that may predispose to type 2 diabetes. Diabetologia 48:732-740

4. Nichols GA, Hillier TA, Brown JB (2008) Normal fasting plasma glucose and risk of type 2 diabetes diagnosis. Am J Med 121:519524
5. Tirosh A, Shai I, Tekes-Manova D et al (2005) Normal fasting plasma glucose levels and type 2 diabetes in young men. $\mathrm{N}$ Engl $\mathrm{J}$ Med 353:1454-1462

6. Abdul-Ghani MA, Lyssenko V, Tuomi T, DeFronzo RA, Groop L (2008) Fasting vs postload plasma glucose concentration and the risk for future type 2 diabetes: results from the Botnia Study. Diabetes Care 32:281-286

7. Dagogo-Jack S, Askari H, Tykodi G (2009) Glucoregulatory physiology in subjects with low-normal, high-normal, or impaired fasting glucose. J Clin Endocrinol Metab 94:2031-2036

8. Brunzell JD, Robertson RP, Lerner RL et al (1976) Relationships between fasting plasma glucose levels and insulin secretion during intravenous glucose tolerance tests. J Clin Endocrinol Metab 42:222-229

9. Utzschneider KM, Prigeon RL, Faulenbach MV et al (2009) Oral disposition index predicts the development of future diabetes above and beyond fasting and 2-h glucose levels. Diabetes Care 32:335-341

10. Grandone A, Amato A, Luongo C, Santoro N, Perrone L, del Giudice EM (2008) High-normal fasting glucose levels are associated with increased prevalence of impaired glucose tolerance in obese children. J Endocrinol Investig 31:1098-1102

11. Thomas JE, Foody JM (2007) The pathophysiology of cardiovascular disease in diabetes mellitus and the future of therapy. J Cardiometab Syndr 2:108-113

12. Nguyen QM, Srinivasan SR, Xu JH, Chen W, Berenson GS (2008) Changes in risk variables of metabolic syndrome since childhood in pre-diabetic and type 2 diabetic subjects: the Bogalusa Heart Study. Diabetes Care 31:2044-2049

13. Expert Committee on the Diagnosis and Classification of Diabetes Mellitus (2003) Report of the Expert Committee on the Diagnosis and Classification of Diabetes Mellitus. Diabetes Care 26:S5-S20

14. Matsuda M, DeFronzo RA (1999) Insulin sensitivity indices obtained from oral glucose tolerance testing: comparison with the euglycaemic insulin clamp. Diabetes Care 22:1462-1470

15. Yeckel CW, Weiss R, Dziura J et al (2004) Validation of insulin sensitivity indices from oral glucose tolerance test parameters in obese children and adolescents. J Clin Endocrinol Metab 89:1096-1101

16. Altman DG (1991) Practical statistics for medical research. Chapman and Hall, London

17. Weiss R, Dziura JD, Burgert TS, Taksali SE, Tamborlane WV, Caprio S (2006) Ethnic differences in beta cell adaptation to insulin resistance in obese children and adolescents. Diabetologia 49:571-579

18. Dabelea D, Bell RA, D'Agostino RB Jr et al (2007) Incidence of diabetes in youth in the United States. JAMA 297:2716-2724

19. Sinha R, Fisch G, Teague B et al (2002) Prevalence of impaired glucose tolerance among children and adolescents with marked obesity. N Engl J Med 346:802-810

20. Libman IM, Barinas-Mitchell E, Bartucci A, Robertson R, Arslanian S (2008) Reproducibility of the oral glucose tolerance test in overweight children. J Clin Endocrinol Metab 93:4231-4237

21. Goran MI, Lane C, Toledo-Corral C, Weigensberg MJ (2008) Persistence of pre-diabetes in overweight and obese Hispanic children: association with progressive insulin resistance, poor betacell function, and increasing visceral fat. Diabetes 57:3007-3012

22. Cali AM, Man CD, Cobelli C et al (2009) Primary defects in betacell function further exacerbated by worsening of insulin resistance mark the development of impaired glucose tolerance in obese adolescents. Diabetes Care 32:456-461

23. Lyssenko V, Jonsson A, Almgren P et al (2008) Clinical risk factors, DNA variants, and the development of type 2 diabetes. N Engl J Med 20(359):2220-2232

24. Coutinho M, Gerstein HC, Wang Y, Yusuf S (1999) The relationship between glucose and incident cardiovascular events. A metaregression analysis of published data from 20 studies of 95,783 individuals followed for 12.4 years. Diabetes Care 22: 233-240 
25. Nathan DM, Lachin J, Cleary P et al (2003) Intensive diabetes therapy and carotid intima-media thickness in type 1 diabetes mellitus. N Engl J Med 348:2294-2303

26. UK Prospective Diabetes Study Group (1998) Tight blood pressure control and risk of macrovascular and microvascular complications in type 2 diabetes: UKPDS 38. BMJ 317:703-713 (erratum in BMJ (1999) 318:29)

27. Shah AS, Dolan LM, Kimball TR et al (2009) Influence of duration of diabetes, glycaemic control, and traditional cardiovascular risk factors on early atherosclerotic vascular changes in adolescents and young adults with type 2 diabetes mellitus. J Clin Endocrinol Metab 94:3740-3745

28. Holman RR, Paul SK, Bethel MA, Matthews DR, Neil HA (2008) 10-year follow-up of intensive glucose control in type 2 diabetes. N Engl J Med 359:1577-1589

29. Stratton IM, Adler AI, Neil HA et al (2000) Association of glycaemia with macrovascular and microvascular complications of type 2 diabetes (UKPDS 35): prospective observational study. BMJ 321:405-412
30. Stettler C, Allemann S, Jüni P et al (2006) Glycaemic control and macrovascular disease in types 1 and 2 diabetes mellitus: metaanalysis of randomized trials. Am Heart J 152:27-38

31. Abraira C, Duckworth W (2003) The need for glycaemic trials in type 2 diabetes. Clin Diabetes 21:107-111

32. Kirkman MS, McCarren M, Shah J, Duckworth W, Abraira C (2006) The association between metabolic control and prevalent macrovascular disease in type 2 diabetes: the VA Cooperative Study in diabetes. J Diabetes its Complicat 20:75-80

33. Duckworth W, Abraira C, Moritz T et al (2008) Glucose control and vascular complications in veterans with type 2 diabetes. N Engl J Med 360:129-139

34. Bell LM, Watts K, Siafarikas A et al (2007) Exercise alone reduces insulin resistance in obese children independently of changes in body composition. J Clin Endocrinol Metab 92:4230-4235

35. Savoye M, Shaw M, Dziura J et al (2007) Effects of a weight management program on body composition and metabolic parameters in overweight children: a randomized controlled trial. JAMA 297:2697-2704 